DOI: http://doi.org/10.4038/jrrisl.v99i0.1890

Journal of the Rubber Research Institute of Sri Lanka (2019) 99, 76-86

\title{
Training induced knowledge and adoption of harvesting technologies in rubber smallholdings in the Kegalle district of Sri Lanka
}

\author{
P K K S Gunarathne*, D M A P Dissanayake*, R A D Ranawaka* and \\ Wasana Wijesuriya**
}

* Rubber Research Institute of Sri Lanka, Telewala Road, Ratmalana, Sri Lanka

** Rubber Research Institute of Sri Lanka, Dartonfield, Agalawatta, Sri Lanka

\begin{abstract}
This study was carried out to evaluate the impact of training on improvement of knowledge and adoption of technologies developed by the Rubber Research Institute of Lanka (RRISL) for harvesting of rubber in the smallholder sector. The scores which were used to measure the knowledge (KNOW) and adoption (ADOP) of latex harvesters on recommendations related to latex harvesting were also used to evaluate whether systematic training could improve knowledge/adoption. Equal number of trained and non-trained harvesters; 80 each were selected for the study in Kegalle district. A questionnaire survey and field level observations were conducted in 2017, employing equal numbers from the two categories; Latex Harvesting Assistants (LHAs) who harvest their own rubber lands $(O P E R=1)$ and those who are hired by land owners $(O P E R=0)$ within the categories of trained and non-trained LHAs. The increase in KNOW and ADOP due to systematic training was statistically significant. The respective mean scores for trained and non-trained groups (for KNOW; 70 and $38, t=-12.85, P<0.001$ and for $A D O P ; 71$ and $40, t=-10.34, P<0.001)$ signifying that training has increased KNOW and ADOP by $84 \%$ and $78 \%$, respectively. In the trained group, significant differences were observed for both KNOW and ADOP for OPER (for KNOW; OPERI=82.9 and OPERO=57.8; $t=-6.45, P<0.001$ ) (for ADOP; $O P E R I=84.3$ and $O P E R O=56.3 ; t=-6.36, P<0.001)$, indicating that $K N O W$ and $A D O P$ to be high with OPERI. The experience in harvesting was negatively correlated with KNOW $(r=-0.528, P<0.001)$ and ADOP $(-0.638, P<0.001)$. Participation in other extension activities was positively related with $\mathrm{KNOW}(r=0.341, P<0.01)$ and ADOP ( $r=0.390, P<0.01)$. The variables, such as age, gender and education level and job satisfaction did not have significant relationships with KNOW and ADOP. It is evident that systematic training on rubber harvesting enhances knowledge and adoption of recommended practices, which may eventually improve the productivity of rubber smallholdings. Hence, this training is worth continuing for the improvement of future performance of the smallholder rubber sector.
\end{abstract}

Key words: harvesting practices of rubber, knowledge and adoption scores, latex harvesting assistants, smallholder rubber sector 


\section{Introduction}

Rubber (Hevea brasiliensis) is one of the major plantation crops in Sri Lanka in terms of export earnings and employment generation and contributed nearly $0.3 \%$ to the GDP in 2018 (Anon., 2018). In the Sri Lankan context, smallholder rubber sector is considered as the most dynamic segment of the rubber sector as it represents $68 \%$ of the total rubber extent of Sri Lanka though it contributes $69 \%$ to the national rubber production, yet far behind the expected targets (Anon., 2017).

Latex is the major economic constituent of the rubber tree which can be extracted during its mature period once the harvestable girth is attained. The rubber tree is exploited by periodic excision of a thin shaving of the bark along a sloping groove placed spirally on the bark of the tree trunk to extract latex from latex vessels by a "tapping knife" and this procedure is known as harvesting. Latex Harvesting Assistant (LHA) is the person who extracts latex from the rubber plant. There are two types of harvesters; LHAs who harvest their own rubber lands and those who are hired by land owners. Harvesting of rubber is a highly skilled task and the LHAs have to be adequately trained to perform harvesting to get the best returns and also to protect the rubber tree to get an optimum economic result over the total lifespan of the tree. Harvesting determines the land productivity of rubber plantations, which is recorded as a low value less than $1000 \mathrm{~kg} / \mathrm{ha} /$ year in the Sri Lankan context (Anon., 2017).

The low adoption in harvesting recommendations formulated by the
Rubber Research Institute of Sri Lanka (RRISL) is one of the key issues which adversely affect the sustainability of rubber farming. Certain repercussions due to this issue could be identified, viz. damaged trees, early uprooting, less potential yield due to poor harvesting quality, abandoning of harvestable holdings which finally lead to low national rubber production (Wijesuriya et al., 2007). Therefore, the adoption in harvesting recommendations is important in meeting up with the national rubber production targets.

RRISL is the nodal agency in the country with the statutory responsibility for research and development of all aspects of rubber cultivation, harvesting and processing for the benefit of the rubber industry and delivers extension services for the rubber sector. Technology transfer through training is one of the strategies in operation by RRISL and a number of novel approaches have been introduced to improve the knowledge and skills of smallholder rubber farmers. The Advisory Services Department (ASD) of RRISL conducts training programmes with a view to improving skills of rubber harvesters. Establishment of "Training Schools for Latex Harvesting Assistants (TSLHAs)" is one of the strategies to address the shortage of skilled LHAs while improving their knowledge which ultimately would help to increase the adoption of correct harvesting practices recommended by RRISL. The TSLHAs is a systematic training programme which is conducted to introduce new skilled LHAs to the rubber smallholder sector as a solution for the shortage of 
skilled harvesting assistants. The TSLHAs is based on a syllabus including both practical and theoretical aspects which are conducted in ten full days. Trainees are provided with both theoretical knowledge and practical skills in rubber harvesting by the Rubber Extension Officers (REOs) at convenient locations. Rubber $\operatorname{logs}$ are used for practical sessions, to practice harvesting with hands on support. At the end of each TSLHAs, trainees are evaluated by both oral and practical tests by the REOs (Anon., 2011). Yet, so far, no studies have been done to quantify the impact of training on improvement of knowledge and adoption of technologies in rubber harvesting. On the other hand, development of combined indices to assess knowledge and adoption levels for each individual LHA considering different components of harvesting makes it easy for comparing and clustering of farmers for further training to improve the adoption levels. The main objective of this study was to investigate the impact of training on knowledge and adoption of harvesting technologies on performance of the smallholder sector.

This paper describes the development of indices for knowledge and adoption of LHAs on recommendations related to latex harvesting employing a participatory approach to ascertain weights for each component of the indices. Through these indices the hypothesis of "whether latex harvester training could improve knowledge/adoption" is also tested for the type of operation, viz. hired or harvesting their own land.

\section{Materials and Methods}

Data collection and sampling procedure The study was conducted in the Kegalle District in Sri Lanka $\left(7.25^{\circ} \mathrm{N}, 80.35^{\circ} \mathrm{E}\right)$ during 2018. The survey was conducted with 160 LHAs in eight REOs regions. The sample was selected randomly after stratification in each REO region (Table 1). In the next step, from this stratified sample on REOs regions, two equal portions were selected based on whether the training received on harvesting at TSLHA or not and these categories were further divided into LHAs operated on hiring basis and who harvest their own rubber lands. A pre-tested questionnaire were used to collect data from the respondents accompanied with field observations. The questionnaire consisted questions to collect information on three main areas; viz. key information of smallholders, questions to test knowledge on recommendations in harvesting of latex and field testing on adoption of these recommended practices in each smallholding harvested by the LHAs.

Table 1. The selected sample of LHAs from different REOs ranges in Kegalle district

\begin{tabular}{lc}
\hline REO range & $\begin{array}{c}\text { No. of Trainees/Non- } \\
\text { trainees }\end{array}$ \\
\hline Kegalle & 13 \\
Yatiyantota & 12 \\
Ruwanwella & 13 \\
Mawanella & 10 \\
Galigamuwa & 14 \\
Dehiovita & 06 \\
Warakapola & 12 \\
Total & 80 \\
\hline
\end{tabular}


P K K S Gunarathne et al.

\section{Testing of knowledge on recommendations in harvesting of latex}

The knowledge is defined as those behaviours and test situations, which emphasize memorizing by either recognition or recall of ideas, materials or phenomena. The knowledge is one of the important components of behaviour and it plays a vital role in the adoption in improved technologies (Bloom et al., 1985). The knowledge becomes the power of a person, so that farmer's technical knowledge determines their ability to reach solutions (Verdiuin et al., 1979).

The technical knowledge of the LHAs was measured using a test, which is performed using a questionnaire. It referred to critical areas of the recommended practices of rubber farming introduced by the RRISL. They are; 1 . Tapping system, 2 . Tapping panel marking, 3. Time of tapping, 4. Girth at opening of tapping, 5. Height at opening of tapping, 6. Placement of spout, 7. Placement of the cup, 8. Cleanliness in tapping area and 9. Cleanliness of tapping utensils. There were five questions (questioned each respondent in the local language) from the abovementioned areas and one mark is awarded for each correct answer. The test/questions were read by the researcher to LHA and scores, 1 for a correct answer and 0 for an incorrect answer was recorded for each question, and the total was calculated for each LHA.

\section{Testing of adoption on recommendations in harvesting of latex}

Rogers and Shoemaker (1971) defined adoption as a decision to make full use of a new idea as the best source of action available. The empirical referent of this concept has to take a time dimension in to account. The field testing on recommendations was done after one year of attending the training session. The adoption levels were also tested on the same areas used for testing the knowledge. For the areas from five to nine, as mentioned for testing of knowledge, randomly selected ten rubber trees were assessed to obtain the adoption level.

The level of adoption in each area was measured using an adoption scale which comprises three different levels of adoption, to which marks were given (2 - Good, 1 - Average and 0 -Poor), which resulted in a score for each recommendation. The final score was taken as a sum of all scores for each recommendation after weighting each recommendation on the priority.

A participatory approach was employed in weighting each recommended practice from one to nine, which were used for developing the knowledge/adoption score. A pair-wise ranking approach was employed to identify the priorities to set the weights for each activity selected to develop the indices. A group of rubber extension officers was involved in the pair-wise ranking exercise.

The equation for the Knowledge and Adoption scores for individual LHA; $K N O W$ and $A D O P$ is given in equation 1. 
KNOW or $A D O P=\frac{\sum_{i=1}^{n}\left(w_{i} * X_{O o b s}\right)}{\sum_{i=1}^{n}\left(w_{i} * \operatorname{Xax}_{i}\right)} *$ 100 (1)

Xobs $_{i}=$ Observed Knowledge or Adoption Score for $i^{\text {th }}$ recommendation Xmax $_{i}=$ Maximum Knowledge or Adoption Score for $i^{\text {th }}$ recommendation $w_{i}=$ Weight for the $i^{\text {th }}$ recommendation

\section{Data analysis}

Descriptive data analysis techniques were employed in this study to identify the differences of knowledge and adoption with training on harvesting related activities. A Correlation analysis was employed in understanding the relationship between knowledge/ adoption scores and other variables of interest. This analysis was done only for the trained group, to understand the impact of other variables listed in Table 2 on $K N O W$ and $A D O P$. The Genstat version 19 was employed in statistical and descriptive analyses.

\section{Key information of LHAs}

The summary of the socio-demographic characteristics of LHAs is presented in Table 3. Female LHAs of both trained and non-trained categories had dominated, with a female: male ratio of nearly 2:1. The age of LHAs varied from 19 to 79 years. The majority of LHAs trained and LHAs non-trained were in the age category of $>51$ years. No one had followed degree programmes or diplomas. Further, only $8 \%$ of both

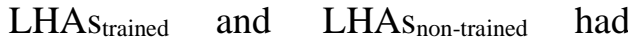
attended tertiary level education (G.C.E. $\mathrm{A} / \mathrm{L}$ ). The majority of the sample (nearly $50 \%$ ) had less than 5 years of experience in harvesting, whilst $23 \%$ had 11 to 15 years of experience and $21 \%$ had 6 to 10 years of experience.

Table 2. Variables used in the analysis

\begin{tabular}{ll}
\hline Variable & Description \\
\hline$A D O P$ & Adoption Score, range from 0 to 100 \\
$K N O W$ & Knowledge Score, range from 0 to 100 \\
$T R A I N$ & Systematic training (Received = 1, Not received=0) \\
$A G E$ & Age of harvester (years) \\
$G E N D E R$ & Gender of harvester (Male = 1, Female =0) \\
$E D U$ & Education level of harvester (Years of formal education) \\
$O P E R$ & Harvesting operation (own land=1, others' land=0) \\
$E X P$ & Experience in harvesting (years) \\
$E X T P A R T$ & Participation in extension programmes (yes=1, no=0) \\
$J S$ & Job satisfaction $(1-$ very unsatisfied, $2-$ unsatisfied, $3-$ unconcerned, \\
& 4- satisfied, 5 - very satisfied) \\
\hline
\end{tabular}


Table 3. The summary of the socio-demographic characteristics of LHAs

\begin{tabular}{lrr}
\hline Characteristics of LHAs & $\begin{array}{r}\text { \% of LHAs } \\
\text { trained }(\mathbf{N}=\mathbf{8 0})\end{array}$ & $\begin{array}{r}\text { \% of LHAs non-trained } \\
(\mathbf{N = 8 0})\end{array}$ \\
\hline $\begin{array}{l}\text { Gender composition } \\
\text { (female) }\end{array}$ & 68 & 70 \\
\hline Age distribution (years) & & \\
$\quad<=25$ & 2 & 2 \\
$26-50$ & 37 & 39 \\
$>51$ & 61 & 59 \\
\hline Level of education & & \\
Up to grade 6 & 9 & 8 \\
Grade 6- O/L & 83 & 7 \\
GCE A/L & 8 & 0 \\
Higher education & 0 & \\
(diploma or degree) & & 23 \\
\hline Experience in harvesting & & 28 \\
$<5$ & 49 & 29 \\
6-10 & 21 & 20 \\
11-15 & 23 & \\
$>16$ & 7 & \\
\hline
\end{tabular}

Development of knowledge score $(K N O W)$ and adoption score (ADOP) The pair-wise ranking exercise revealed priorities for different criteria as listed under prioritization in Table 4. The weights for each criteria were decided based on prioritization as given in Table 4 and the maximum score could be obtained, which is 90 , is presented as a percentage to derive both KNOW and $A D O P$ according to equation 1 .

Table 4. Priority, weights and maximum scores for each criteria for the Knowledge (KNOW) and Adoption Score (ADOP)

\begin{tabular}{lrrr}
\hline Criteria & Priority & $\begin{array}{r}\text { Weight based } \\
\text { on prioritization }\end{array}$ & $\begin{array}{r}\text { Maximum score for } \\
\text { each criterion }\end{array}$ \\
\hline 1. Tapping system & 2 & 3 & 15 \\
2. Tapping panel marking & 4 & 2 & 10 \\
3. Correct time of tapping & 4 & 2 & 10 \\
4. Girth at opening for tapping & 1 & 3 & 15 \\
5. Height at opening for tapping & 3 & 3 & 15 \\
6. Cleanliness of tapping area & 4 & 2 & 10 \\
7. Cleanliness of tapping utensils & 5 & 1 & 5 \\
8. Placement of spout & 6 & 1 & 5 \\
9. Placement of cup & 7 & 1 & 5 \\
\hline
\end{tabular}

Score $=$ highest mark $\mathrm{x}$ weight 
Descriptive statistics of knowledge score $(K N O W)$ and adoption score (ADOP)

The impact of training is evident according to the information given in Table 5 and Fig. 1, that the systematic training through TSLHAs has improved both knowledge and adoption on harvesting related practices in rubber faming. Systematic training has increased $K N O W$ and $A D O P$ by $84 \%$ and $78 \%$, when compared to the non-trained group. It is also noted that the variability in the 'trained' group is high compared to the 'non-trained' group. The results of t-tests suggest that there are significant differences between the means of trained and non-trained groups for $K N O W$ and $A D O P$ with $\mathrm{t}=-12.85, \mathrm{P}<0.001$ and $\mathrm{t}=$ $-10.34, \mathrm{P}<0.001$, respectively.
It is also important to explore whether the LHAs who tap their own rubber lands $(\mathrm{OPER}=1)$ and others' lands $(\mathrm{OPER}=0)$ behave in a similar way with respect to acquiring knowledge and adoption of technologies in tapping operations. It was observed that in the non-trained group, there was no significant difference between $K N O W$ for OPER $(\mathrm{OPER} 1=36.4$ and OPER0 $=38.6 ; \mathrm{t}=1.2$, $\mathrm{P}=0.234)$ while it was significant for $A D O P$ for OPER (OPER $1=43.5$ and OPER0=35.5; t=-3.37, $\mathrm{P}<0.001$ ) (Fig. $2)$. In the trained group, significant differences were observed for both $K N O W$ and $A D O P$ for OPER (for $K N O W$ : OPER $1=82.9$ and OPER0 $=57.8$; $\mathrm{t}=-6.45, \quad \mathrm{P}<0.001$ ) (for $A D O P$ : OPER $1=84.3$ and OPER $0=56.3 ; \mathrm{t}=-6.36$, $\mathrm{P}<0.001$ ) (Fig. 3).
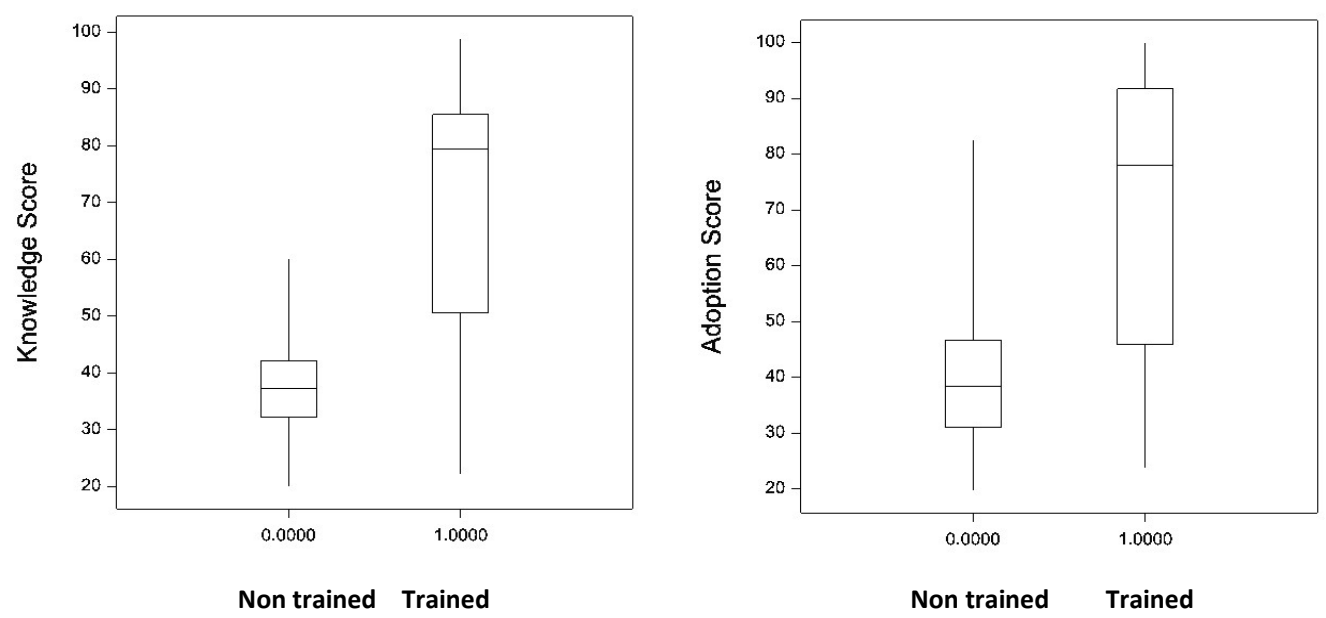

Fig. 1. The distribution of Knowledge Score $(K N O W)$ and Adoption Score $(A D O P)$ for trained and non-trained LHAs 
P K K S Gunarathne et al.

Table 5. Descriptive statistics of Knowledge Score (KNOW) and Adoption Score (ADOP)

\begin{tabular}{|c|c|c|c|c|}
\hline \multirow{3}{*}{ Statistic } & \multicolumn{4}{|c|}{ Whether trained on harvesting techniques } \\
\hline & \multicolumn{2}{|c|}{ Yes } & \multicolumn{2}{|c|}{ No } \\
\hline & KNOW & $A D O P$ & KNOW & $A D O P$ \\
\hline Mean & 70 & 71 & 38 & 40 \\
\hline Maximum & 99 & 100 & 20 & 83 \\
\hline Minimum & 22 & 24 & 60 & 20 \\
\hline SD & 21 & 24 & 8 & 11 \\
\hline
\end{tabular}
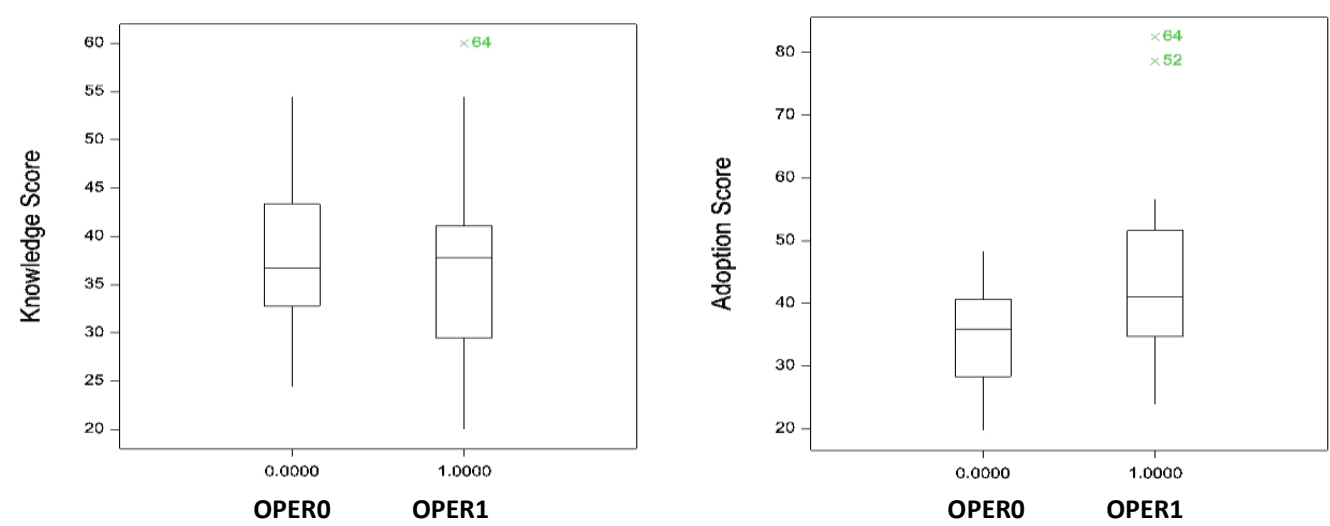

Fig. 2. The distribution of Knowledge Score $(K N O W)$ and Adoption Score $(A D O P)$ for the nontrained group under type of tapping operation (OPER1: tapping the own land and OPER0: tapping in others' land)
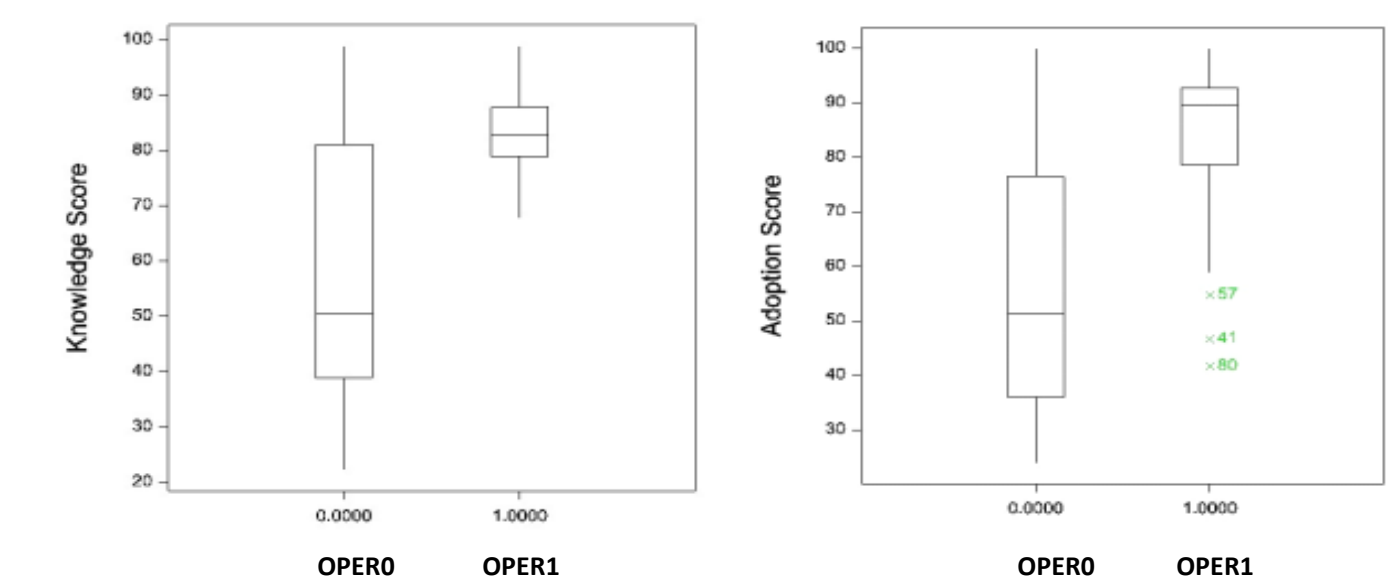

Fig. 3. The distribution of Knowledge Score (KNOW and Adoption Score (ADOP) for the trained group under type of tapping operation (OPER1: tapping the own land and OPER0: tapping in others' land) 


\section{Relationship between $K N O W$ and $A D O P$ and its relationship with participation in harvester training}

Obviously, there is a positive relationship between knowledge and adoption as described by a number of authors (Sivayoganathan, 1982; Amarasinghe (1993); Niranjan et al., 1991). In this study as shown in Fig. 4, a positive correlation was observed between $K N O W$ and $A D O P$. Yet, the strength of the relationship is more pronounced in the trained group. It suggests that systematic training on rubber harvesting would enhance the adoption of recommended practices which would eventually improve the productivity of rubber plantations.
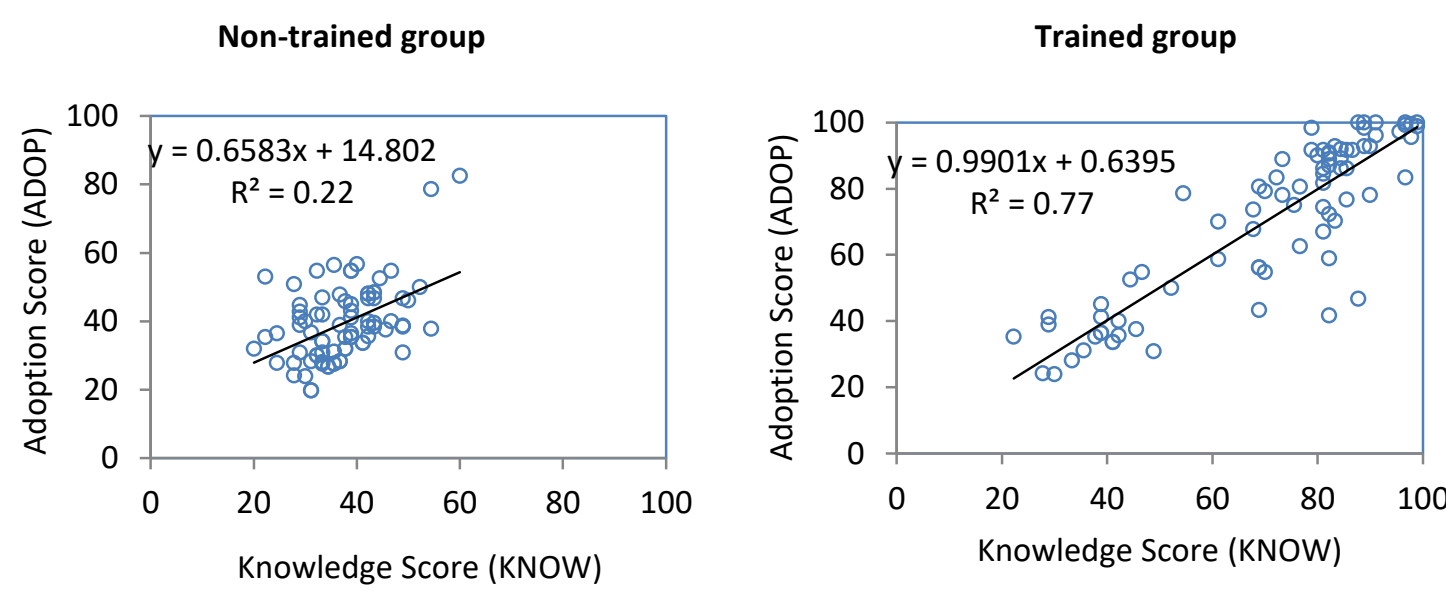

Fig. 4. The relationship of Knowledge Score $(K N O W)$ and Adoption Score $(A D O P)$ for trained and non-trained LHAs

Correlation analysis of $K N O W$ and $A D O P$ with relevant sociodemographic variables

Harvesting operation (Owner $=1$, Hired $=0$ ) yielded a positive correlation (Table 6) with $K N O W$ and $A D O P$ suggesting the scores would be higher when the owner harvest the rubber land. It is evident from Table 6, that experience in years $(E X P)$ is negatively correlated with $K N O W$ and $A D O P$, which means grasping of knowledge and motivation in adoption, especially in harvesting of rubber is in contrary to prior experience on harvesting. As expected, participation in other extension activities (EXTPART) is positively related with $K N O W$ and $A D O P$, as evident from Table 6 . It is also interesting to note that $A G E$, GENDER and $E D U C$ do not have significant relationships with $K N O W$ and $A D O P$. The relationship with job satisfaction $(J S)$, although not significant, showed a positive correlation. 
Table 6. Correlations of adoption score $(A D O P)$ and knowledge score (KNOW) with relevant variables listed in Table 2

\begin{tabular}{lcc}
\hline Variable & \multicolumn{2}{c}{ Correlation coefficients } \\
\cline { 2 - 3 } & KNOW & $\boldsymbol{A D O P}$ \\
\hline$A G E$ & 0.112 & 0.105 \\
GENDER & 0.015 & 0.079 \\
$E D U$ & -0.002 & 0.076 \\
OPER & $0.523^{* * * *}$ & $0.564 * * *$ \\
EXP & -0.528 & $-0.638^{* * *}$ \\
$J S$ & 0.341 & 0.390 \\
\hline
\end{tabular}

Note: **, *** Statistically significant at 0.01 and 0.001 , respectively

\section{Conclusion}

Systematic training through TSLHAs had enhanced knowledge and adoption of harvesting recommendations/ practices by $84 \%$ and $78 \%$, respectively, when compared to the non-trained group of LHAs.

There was a positive and strong correlation observed between both knowledge and adoption for trained LHAs. Harvesting operation yielded a positive correlation with knowledge and adoption indicating that scores were higher when the owner harvests the rubber land. The experience in harvesting was negatively correlated with knowledge and adoption. The participation in other extension activities was positively related with knowledge and adoption. The age, gender and education level of harvesters did not have significant relationships with knowledge and adoption. Their relationship with job satisfaction, although not significant, showed a positive correlation.

Systematic training through TSLHAs on rubber harvesting would enhance the knowledge and adoption of recommended practices which will eventually improve the productivity of rubber smallholdings. Hence, this practice is worth continuing for the future for improved performance of the smallholder rubber sector.

\section{Acknowledgements}

The authors are grateful to the Rubber Extension Officers of Kegalle district under the Advisory Services Department of RRISL and the LHAs in Kegalle district for their valuable support.

\section{References}

Amarasinghe, A P (1993). Evaluation of sugarcane farming practices and identification of training needs of smallholder sugarcane farmers, Unpublished BSc research report, Faculty of Agriculture, University of Peradeniya.

Anon. (2018). Annual Report, Central Bank of Sri Lanka, Colombo, Sri Lanka, 2018, 25-37.

Anon. (2017). Statistical Information on Plantation Crops 2017, Ministry of Plantation Industries, Battaramulla, Sri Lanka, 2017, 100-120.

Anon. (2011). Annual Review. Rubber Research Institute of Sri Lanka, Agalawatta, Sri Lanka, 2011, 126-139.

Bloom, M, Egalhlt, M, Farst, E, Hill, W and Karthwool, P R (1985). Taxonomy of Education Objectives. The cognitive domain, Longmans Green and Company, New York, 1985, 95-107.

Niranjan, S K D F F, Jayatilake, M W A P and Thattil, R O (1991). Factors associated with the adoption of the sixrow rice trans planter machine. Tropical Agricultural Research 3, 276-289.

Rogers, E M and Shoemaker, F F (1983). Communication of innovation: A cross 
cultural approach. The Free Press, New York, 1971, 65-74.

Sivayoganathan, C (1982). Importance of contact farmers as a source of information in the adoption of selected rice production practices among farmers in Anuradhapura district, Sri Lanka. Unpublished PhD Thesis, Texass A \& M University, USA.

Verduin, J R, Miller, H D and Greer, C E (1979). Adults Teaching Adults: Principals and strategies, Learning concepts. Austin, Texas, 45-67.

Wijesuriya, W, Dissanayake, D M A P, Herath, $\mathrm{K}$, Edirisinghe, $\mathrm{J}$ and
Abewardana, V (2007). Some issues related to sustainability in the smallholder rubber sector: a case study of three major rubber growing districts. Journal of Rubber Research Institute of Sri Lanka 88, 59-76.

Address for correspondence: $\mathrm{Mr} \mathrm{P} \mathrm{K}$ K S Gunarathne, Advisory Officer, Advisory Services Dept., Rubber Research Institute of Sri Lanka, Telewala Road, Ratmalana, Sri Lanka.

e-mail: kapila.s.gunarathne@gmail.com 